\title{
Large Eddy Simulation of Flow around a Square Cylinder
}

\author{
Z. G. Xie, C. X. Xu*, G. X. Cui, Z. S. Zhang \\ Department of Engineering Mechanics, Tsinghua University, Bcijing 100084, China \\ Email: xucx@tsinghua.edu.cn
}

\begin{abstract}
The three dimensional turbulent flow around a square cylinder at Reynolds number of 22,000 is numerically studied by large eddy simulation (LES). The mixed finite-volume finitc-element method with unstructured tetrahedron elements is used to solve the filtered compressible Navier-Stokes equations at low Mach number. The preconditioning method, the character length in outlet boundary condition and the sub-grid models are tested through 6 test cases (denote T1 T6). It is found that by properly setting the computational parameters, the recirculation length, the drag coefficient and the recovery velocity, which supposed to be highly scnsitive to spatial resolution, can be predicted with sufficient accuracy with the relatively coarse grids. The bulk mean parametcrs obtained in present simulations are shown in Table 1, in which $S t$ denotes the Strouhal number, $X r$ the recirculation length, $\bar{C}_{L}$ and $\bar{C}_{D}$ represent the time-averaged lift and drag coefficients, $C_{L}^{\prime}$ and $C_{D}^{\prime}$ the root-mean square of the lift and drag coefficients, respectively. The present results are in good agreement with the literature results
\end{abstract}

Table 1 Bulk mean parameters

\begin{tabular}{ccccccc}
\hline Case & $S t$ & $X r$ & $\bar{C}_{L}$ & $\bar{C}_{L}^{\prime}$ & $\bar{C}_{D}$ & $C_{D}^{\prime}$ \\
\hline T1 & 0.133 & 1.38 & -0.019 & 1.06 & 2.13 & 0.18 \\
T2 & 0.134 & 2.03 & 0.027 & 0.50 & 2.00 & 0.12 \\
T3 & 0.121 & 1.44 & -0.014 & 1.07 & 2.17 & 0.29 \\
T4 & 0.129 & 1.21 & -0.079 & 1.22 & 2.22 & 0.23 \\
T5 & 0.128 & 1.38 & 0.015 & 1.12 & 2.12 & 0.18 \\
T6 & 0.134 & 1.23 & -0.065 & 1.18 & 2.16 & 0.15 \\
Lyn [5] & 0.132 & 1.38 & & & 2.1 & \\
Luo [7] & 0.13 & & & 1.21 & 2.21 & 0.18 \\
Grigoriadis [3] & 0.132 & 1.35 & -0.004 & 1.03 & 1.95 & 0.111 \\
\hline
\end{tabular}

\section{REFERENCES}

1. Voke PR. Flow past a square cylinder: test case LES2. In: Chollet JP, Voke PR, eds. Direct and Large-Eddy Simulation II. Kluwer Academic Publishers: Dordrecht, 1996; 355-373

2. Rodi W, Ferziger JH, Breuer M, Pourquie. M. Status of large eddy simulation: Results of a workshop. Journal of Fluids Engineering, 1997;119:248-262

3. Grigoriadis DGE, Bartzis JG, Goulas A. LES of the flow past a rectangular cylinder using the immersed boundary concept. Int. J. Numer. Meth. Fluids, 2003;41:615-632

4. Camarri S, Salvetti, MV, Koobus B, Dervieux A. Large eddy simulation of a bluff-body flow on unstructured grids. Int. J. Num. Meth. Fluids, 2002;40:1431-1460

5. Lyn DA, Einav S, Rodi W, Park JH. A laser-doppler velocimetry study of cnsemble-averaged characteristics of the turbulent near wake of a square cylinder. J. Fluid Mech. 1995;304:285-318

6. Poinsot TJ, Lele SK. Boundary conditions for direct simulations of compressible viscous flows. $J$. Comp. Phys., 1992;101:104-129

7. Luo SC, Yazdani MDG, Chew YT, Lee TS. Effects of incidence and afterbody shape on flow past bluff cylinders. J. Indu. Aero., 1994;53:375-399 